\title{
Modular ESS with Second Life Batteries Operating in Grid Independent Mode
}

\author{
N. Mukherjee \\ Power Engineering \& Power Electronics Group \\ Department of Electrical, Electronic \& Power Engineering \\ Aston University \\ Birmingham, B4 7ET, United Kingdom \\ Email: mukhern2@aston.ac.uk
}

\author{
D. Strickland \\ Power Engineering \& Power Electronics Group \\ Department of Electrical, Electronic \& Power Engineering \\ Aston University \\ Birmingham, B4 7ET, United Kingdom \\ Email: d.strickland@aston.ac.uk
}

Abstract - This work is part of a bigger project which aims to research the potential development of commercial opportunities for the re-use of batteries after their use in low carbon vehicles on an electricity grid or microgrid system. There are three main revenue streams (peak load lopping on the distribution Network to allow for network re-enforcement deferral, National Grid primary/ secondary/ high frequency response, customer energy management optimization). These incomes streams are dependent on the grid system being present. However, there is additional opportunity to be gained from also using these batteries to provide UPS backup when the grid is no longer present. Most UPS or ESS on the market use new batteries in conjunction with a two level converter interface. This produces a reliable backup solution in the case of loss of mains power, but may be expensive to implement. This paper introduces a modular multilevel cascade converter (MMCC) based ESS using second-life batteries for use on a grid independent industrial plant without any additional onsite generator as a potentially cheaper alternative. The number of modules has been designed for a given reliability target and these modules could be used to minimize/eliminate the output filter. An appropriate strategy to provide voltage and frequency control in a grid independent system is described and simulated under different disturbance conditions such as load switching, fault conditions or a large motor starting. A comparison of the results from the modular topology against a traditional two level converter is provided to prove similar performance criteria. The proposed ESS and control strategy is an acceptable way of providing backup power in the event of loss of grid. Additional financial benefit to the customer may be obtained by using a second life battery in this way.

Keywords - Energy Storage System (ESS), Second-life batteries, Grid independent Operation, Voltage and Frequency Control

\section{INTRODUCTION}

Transportation with battery systems such as hybrid or electric vehicles is increasing in number and there is significant interest in using the electric vehicle batteries to help support the new smart grid functionality. There are several figures banded about from a number of sources including the DECC and Arup and Cenex [1] reports which indicate anything from 70,000 to 2.6 million electric and hybrid vehicles on the road by 2020 . Once the vehicle battery has degraded to around 70 $80 \%$ of its capacity it is considered to be at the end of its first life application. Assuming a battery capability of around 5$18 \mathrm{kWhr}$ (MHEV 5kWh - BEV 18kWh battery) and a 10 year life span, this equates to a projection of battery storage capability available for second life of $>1$ GWhrs by 2025 . Second life batteries should be available at lower cost than new batteries but reliability becomes an important issue as individual batteries may suffer from degraded performance or failure.

This research aims to increase battery life thereby increasing the residual value of batteries (and their vehicles) and contribute to the development of commercial opportunities from automotive battery re-use [2] (peak load lopping, primary/secondary/high frequency response, optimising customer energy demand patterns). All of these incomes streams require the grid system being present. However, there is additional opportunity to be gained from also using these batteries in grid independent mode when the main power source is not present. This paper concentrates on supplying grid independent industrial plant without using additional onsite generators. Industrial plants have multiple loads including motors in pumps, fans and compressors which may be operated frequently [3]. The plant can therefore undergo voltage and frequency fluctuations under both normal and fault operation. For large establishments, multiple power sources/generators can be used and it is not unusual to use battery storage to provide short term power and then, after run up time, to switch to a diesel generator. The diesel generators are not very efficient and also not capable of providing very fast dynamic response (due to the lag time in the AVR/Governor control systems).

This paper investigates the converter interface topology and the control techniques necessary to ensure good frequency and voltage control in a gird independent condition in conjunction with $2^{\text {nd }}$ life battery systems using modeling and simulation. 


\section{SECOND LIFE BATTERY CONVERTER TOPOLOGY}

Most BESS and UPS systems use new batteries along with two level converter interfaces. This type of converter is well established and has a proven track record [4-5] (as shown in Fig. 1). The reliability of the switches and DC-link capacitor tends to decrease with voltage levels and a bulky filter (LC or LCL) is required for grid connection to meet grid standards (such as IEEE519 1992). With new or high performance batteries such as lithium ion, the cost of the energy storage system becomes significant in large installations. Moreover, the, reliability of such an ESS depends mainly on the switches and the DC-link capacitances.

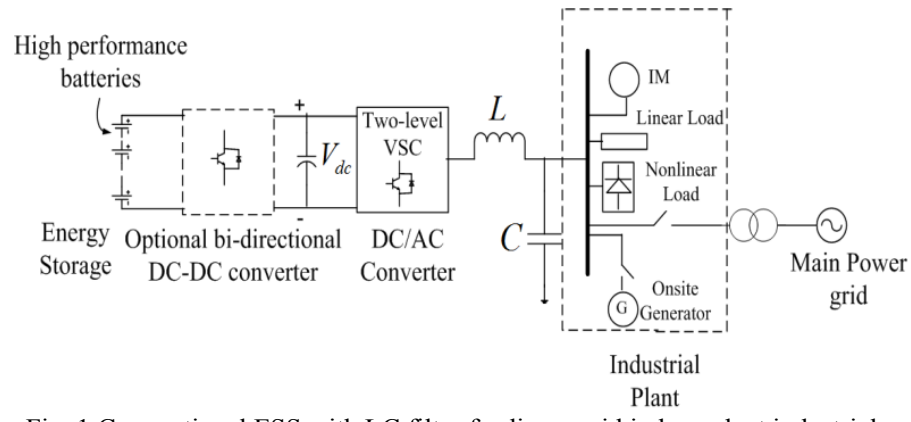

Fig. 1 Conventional ESS with LC filter feeding a grid independent industrial plant

Fig. 2 shows the reliability block diagram of a conventional ESS with the failure rates of each component. It can be clearly seen from equation (1) that the overall reliability of this converter topology is heavily dependent on the number of series connected batteries. Consequently this topology will have poor reliability if second life batteries with higher failure rates are used. Detailed reliability calculations were carried out to find suitable converter topologies [6]. Cascaded multilevel converter with integrated storage or an MMCC [7, 8] was found to be one such suitable converter topology. This paper uses this converter topology along with sufficient module redundancy (k-out-of-n) for connecting to a grid independent plant as shown in Fig. 3. One added advantage of using high module redundancy apart from reliability is an opportunity to reduce filter size at the output. Moreover, active redundant modules could be intelligently controlled to provide longer support to the loads if needed.

Fig. 4 shows a parallel reliability structure where a lower numbers of series batteries and a larger numbers of modules has been used. The parallel reliability diagram emphasizes reasonable reliability can be obtained. The expression of overall reliability in a parallel system is given in equation (2) where $R_{m}$ is the reliability of a single module.

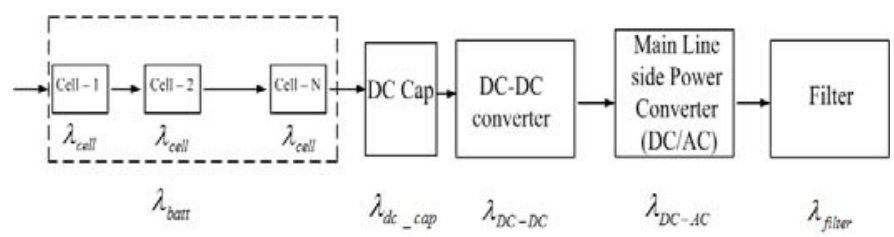

Fig. 2 Series Reliability Block Diagram (RBD) of Conventional ESS

$$
\lambda_{T}=N \lambda_{\text {cell }}+\lambda_{D C-D C}+\lambda_{d c_{-} \text {cap }}+\lambda_{D C-A C}+\lambda_{\text {filter }}
$$

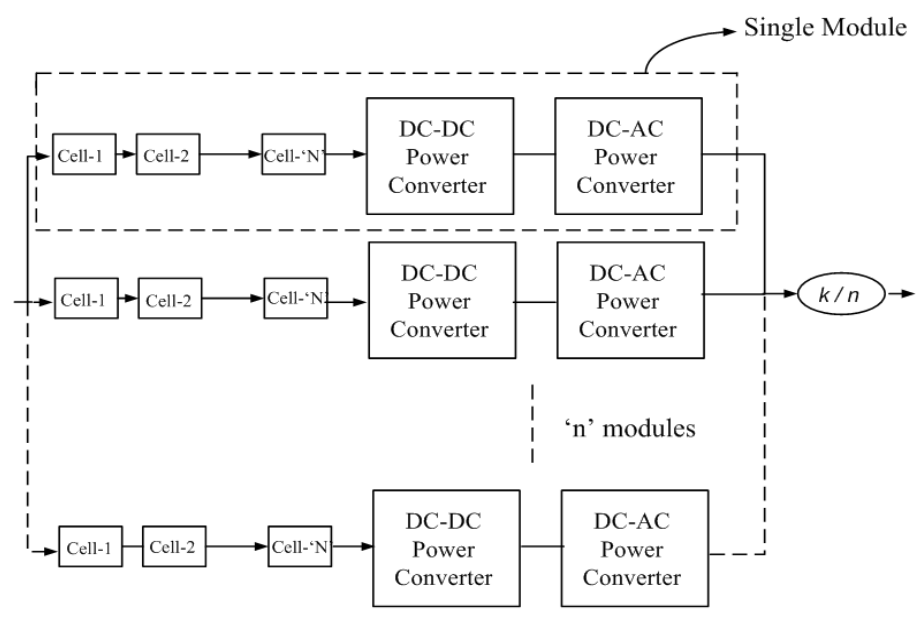

Reliability diagram (RBD) with

$$
\text { ' } \mathrm{k} \text { '-out-of-'n' redundancy }
$$

Fig. 4 Parallel Reliability Block Diagram (RBD) of Modular ESS

$$
R(k, n)=\sum_{i=k}^{n} C_{i}^{n} R_{m}^{i}\left(1-R_{m}\right)^{n-i}
$$

Apart from reliability advantages for $2^{\text {nd }}$ life battery systems this converter can provide some additional advantages over a conventional topology, such as:

- Enhanced fault-tolerant capability both on battery side as well as on ac side

- Individual battery module handling capability

- $\quad$ Potentially lower THD at customer ac grid.

- Possible elimination line/ac side transformer

- Additional support (for longer time) to grid independent plant

- Higher efficiency at a high power level

- The avoidance of a single large DC-link capacitance

Past research investigated this modular converter in a BESS [14-15]. However, the research primarily concentrated on issues in grid connected system where power quality and voltage levels were the main focus. Grid independent mode without additional generation requires different control techniques compared to those reported.

\section{MODELLING AND CONTROL}

Frequency control in a grid connected system has been widely discussed in literature [12-13], where an active power (P) - frequency (f) droop technique is used. Operation with a frequency controller in grid independent plant with onsite generation ( $\mathrm{p}-\mathrm{f}$ droop method) has also been studied for an HVDC system. The authors simulated a two-level converter interface with an LC filter which required sufficient sensors on the grid side to help stability. Traditional droop control strategy becomes less valid in grid independent mode where no additional generation is present and the dependency 


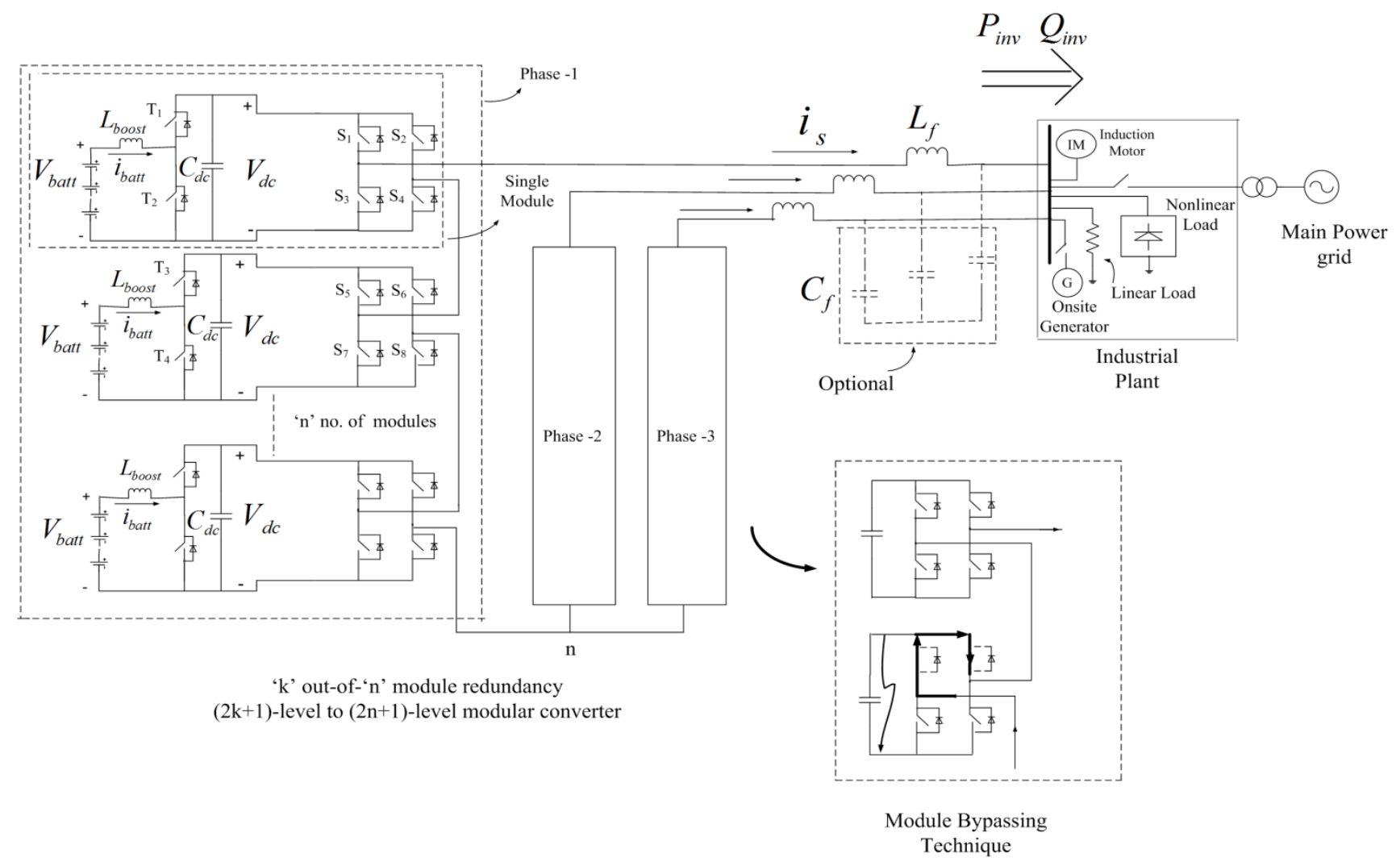

Fig. 3 Second life battery based modular ESS feeding a grid independent industrial Plant with L filter.

between $\mathrm{P}$ and $\mathrm{f}$ is lost, for example, when a large on-line motor starts.

A conventional UPS/BESS system may use a fixed frequency controller along with different voltage control strategies in grid independent mode. This strategy performs well in localized grid independent mode where other onsite generations are not present [9-10]. However, in a large islanded system where multiple onsite generators are present a fixed frequency controller is not suitable and droop control is needed. In such a case, without variable frequency control the desired performance cannot be achieved because frequency tends to fluctuate under sudden load switching or direct online motor starting [11]. This paper describes the addition of a virtual PLL which could simplify the transition from grid independent mode to the case where alternative generation is present and P-f (variable frequency) control is required. The paper also introduces an alternative to fixed frequency control; a reactive power $(\mathrm{Q})$ - frequency (f) based control strategy. This can be applied to a modular converter with minimal/no filter at output. The proposed control strategy with both $\mathrm{L}$ and LC filter has been compared with a conventional scheme through simulation studies on a test $10 \mathrm{MW}, 3.3 \mathrm{KV}$ system.

Table 1 shows a summary of each of the methods used for frequency control along with the associated topology. Three models have been simulated; a conventional converter, an MMCC converter with L-C filter and an MMCC converter with an L filter. All the control techniques have been tested.
However, only those in bold in Table 1 are presented.

A comparison of the results from the modular topology against a traditional two level converter is presented to ensure similar performance criteria. The simulation studies test the dynamic performance of a typical customer network of $10 \mathrm{MW}, 3.3 \mathrm{KV}$ industrial plant under different conditions of grid independent operation such as load switching, direct on-line motor starting and overload/fault conditions. The customer load has been modeled as a $50 \mathrm{~Hz}$ based Industrial plant with a combination of three types of load - linear, nonlinear and induction motors. This type of load often has voltage dip problems on motor starting and it could be difficult to maintain stability because of low system inertia.

TABLE I. FREQUENCY CONTROL TECHNIQUES

\begin{tabular}{|c|c|c|c|c|}
\hline \multirow[t]{3}{*}{ Topology } & \multirow{3}{*}{$\begin{array}{l}\text { Grid } \\
\text { connected } \\
\text { P-f droop }\end{array}$} & \multicolumn{3}{|c|}{ Grid Independent } \\
\hline & & \multirow{2}{*}{$\begin{array}{l}\text { With onsite } \\
\text { Generation } \\
\text { P-f droop }\end{array}$} & \multicolumn{2}{|c|}{ Without onsite generation } \\
\hline & & & Fixed freq. & Q-f droop \\
\hline $\begin{array}{l}2 \text { stage } \\
\text { (convent- } \\
\text { ional) }\end{array}$ & Yes & Yes & Control 1 & Control 3 \\
\hline $\begin{array}{l}\text { MMCC } \\
\text { with LC } \\
\text { filter }\end{array}$ & Yes & Yes & Control 1 & Control 3 \\
\hline $\begin{array}{l}\text { MMCC } \\
\text { with } \quad \text { L } \\
\text { filter }\end{array}$ & Yes & Yes & Control 2 & Control 4 \\
\hline
\end{tabular}




\section{A. DC-DC Converter Model and Control}

The dc-dc converters in each module of the MMCC converters are identical. The total battery voltage is denoted by $\mathrm{V}_{\text {batt }}$. The output voltage of each module is controlled to $\mathrm{V}_{\mathrm{dc}}$ under normal condition. Therefore, any voltage between $\mathrm{kV}_{\mathrm{dc}}$ and $\mathrm{nV}_{\mathrm{dc}}$ (k-out-of-n redundancy) voltage is available. The dynamics of dc-dc converter are described by equations (3) and (4) where ' $D$ ' is the steady state duty ratio depending on boost ratio of the converter. Fig. 5 shows the control block diagram of each dc-dc converter module where the outer dclink voltage loop controls output voltage while the inner loop makes sure battery current remains within stable limits. In the case of a fault on one or more battery cells, the corresponding ac-module bypasses that particular module so that total operation remains uninterrupted.

$$
\begin{aligned}
& L_{\text {boost }} \frac{d i_{\text {batt }}}{d t}+(1-D) V_{d c}=V_{\text {batt }} \\
& C_{d c} \frac{d V_{d c}}{d t}=(1-D) i_{\text {batt }}-i_{\text {load }}
\end{aligned}
$$

The same control signals have been given to all the dc-dc modules in order to have a modular control strategy in the simulation. It is also possible to implement distributed control scheme where each module can be controlled to separate dclink voltages to optimize battery performance. However, this requires more controller PWM hardware which could increase controller cost.

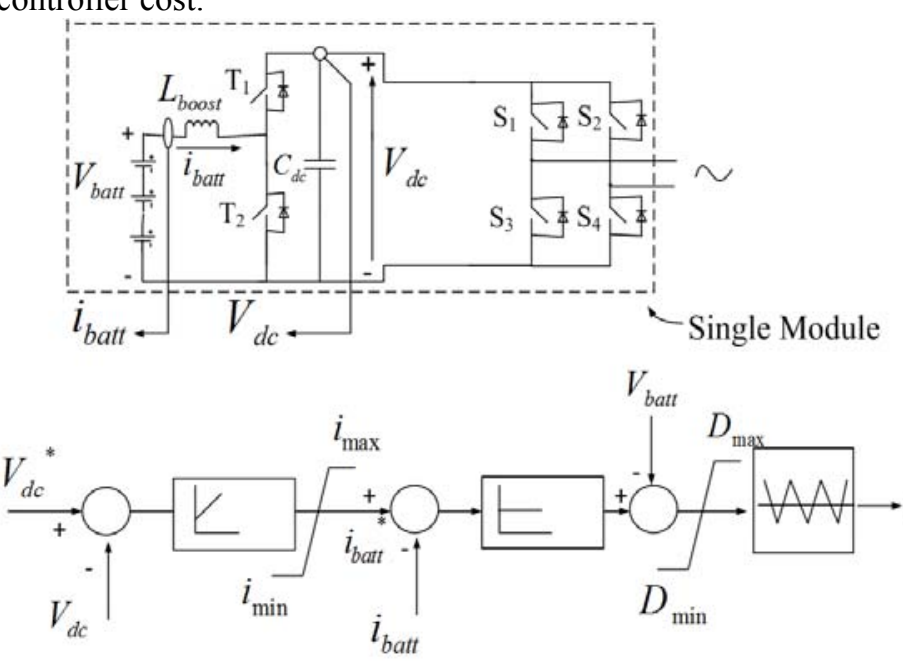

Fig. 5 Modular control of dc-dc converter

\section{B. MMCC Converter with an LC filter Model}

Fig. 6 shows an overview of the control structure of the MMCC in grid independent mode. It is to be noted that the even though a $L_{f}-C_{f}$ filter is modeled the size of $L_{f}$ or $C_{f}$ is less than in a conventional two-level converter. In the presence of the output capacitance $\mathrm{C}_{\mathrm{f}}$ the converter behaves as a voltage source to the loads in grid independent condition. It is not mandatory to control converter output inductor current. However, in order to minimize resonant oscillation and ensure stability an inner current loop is needed. Load current can be sensed or estimated. Power delivered by the converter is denoted by $\mathrm{P}_{\text {inv }}$ and $\mathrm{Q}_{\text {inv }}$ which is considered to be equal to $\mathrm{P}_{\text {load }}$ and $\mathrm{Q}_{\text {load }}$ at steady state.
The dynamics of the system are described by equations (5) and (6) where $U_{\text {inv }}\left(=\mathrm{mV}_{\mathrm{dc}}, \mathrm{m}=\right.$ modulation index of the converter) and $V_{c}$ are the equivalent voltage of the PWM converter and main plant bus respectively.

$$
\begin{aligned}
& L_{f} \frac{d i_{s}}{d t}+R i_{s}+V_{c}=k U_{i n v} \\
& C_{f} \frac{d V_{c}}{d t}=i_{s}-i_{\text {load }}
\end{aligned}
$$

The state variables $\left(\mathrm{V}_{\mathrm{c}}, \mathrm{i}_{\mathrm{s}}\right)$ can be transformed to rotating $\mathrm{d}-\mathrm{q}$ domain using the relations $i_{s}=\left(i_{s d}+i_{s q}\right) e^{j \theta}$ and $V_{c}=\left(V_{c d}+\right.$ $\left.j V_{c q}\right) e^{j \theta}$, to give equations (7) - (10). Note: ' $\theta$ ' is the angle of rotation. ' $q$ '-axis has been taken as real power axis while ' $d$ 'axis represents reactive power axis. Therefore, $i_{\mathrm{sq}}$ is controlled to control real power while $i_{s d}$ is controlled for reactive power.

$$
\begin{aligned}
& L_{f} \frac{d i_{s d}}{d t}+R i_{s d}-\Phi L_{f} i_{s q}+V_{c d}=k U_{\text {invd }} \\
& L_{f} \frac{d i_{s q}}{d t}+R i_{s q}+\Phi L_{f} i_{s d}+V_{c q}=k U_{\text {invq }} \\
& C_{f} \frac{d V_{c d}}{d t}-\omega V_{s q}=i_{s d}-i_{\text {loadd }} \\
& C_{f} \frac{d V_{c q}}{d t}+\omega V_{s d}=i_{s q}-i_{\text {loadq }}
\end{aligned}
$$

\section{MMCC Converter with L-filterModel}

It should be noted that that this operation is possible only when the multilevel converter has a reasonable number of levels. Without the filter capacitor, the dynamics of the converter depends on converter current rather than converter voltage and behaves as a current source. The presence of only one state variable ' $\mathrm{i}_{\mathrm{s}}$ ' makes the control structure inherently more stable than for an $\mathrm{L}-\mathrm{C}$ filter structure.

The dynamics of the system are described by equation (12) where $\mathrm{U}_{\text {inv }}\left(=\mathrm{mV}_{\mathrm{dc}}, \mathrm{m}=\right.$ modulation index of the converter $)$ and $\mathrm{V}_{\mathrm{c}}$ are the equivalent voltage of the PWM converter and main plant bus respectively.

$$
L_{f} \frac{d i_{s}}{d t}+R i_{s}+V_{c}=k U_{i n v}
$$

The state variable $\left(\mathrm{i}_{\mathrm{s}}\right.$ ) can be transformed to a rotating $\mathrm{d}-\mathrm{q}$ domain giving equations (7) and (8) as before.

\section{Generalized Voltage Control Strategy}

The frequency of the grid independent system can be fixed by the controller (fixed frequency control). However, to ease transitions between operating modes, this signal can be passed into a virtual PLL measurement - equation (11) for use with the controller

$$
\frac{d \theta}{d t}=\omega
$$

In grid connected mode the PLL measures the system frequency processing reactive axis voltage i.e d-axis voltage $\mathrm{V}_{\text {cd }}$ to zero. However, in grid independent mode the frequency measurement is done through a virtual PLL which also processes the $d$-axis voltage $V_{c d}$ through a filter such a way that it becomes zero in steady state. In order to have a correct measurement of frequency $V_{c d}$ must be zero at steady state. Therefore the transient change in $\mathrm{V}_{c d}$ causes a change in the 
frequency of the grid independent plant. $\mathrm{V}_{\mathrm{cq}}$ becomes the steady state voltage of the plant power bus (control 1). In an MMCC converter with $\mathrm{L}$ filter the virtual PLL processes daxis current $i_{\text {sd }}$ rather than $V_{\text {cd }}$ through a filter in such a way that it becomes zero in steady state. Therefore the transient change in $i_{\text {sd }}$ causes a change in frequency of the grid independent plant. $\mathrm{V}_{\mathrm{sq}}$ becomes the steady state voltage of the plant (control 2). Where variable frequency control is used (control 3 and 4), the measured PLL is passed directly to the controller.
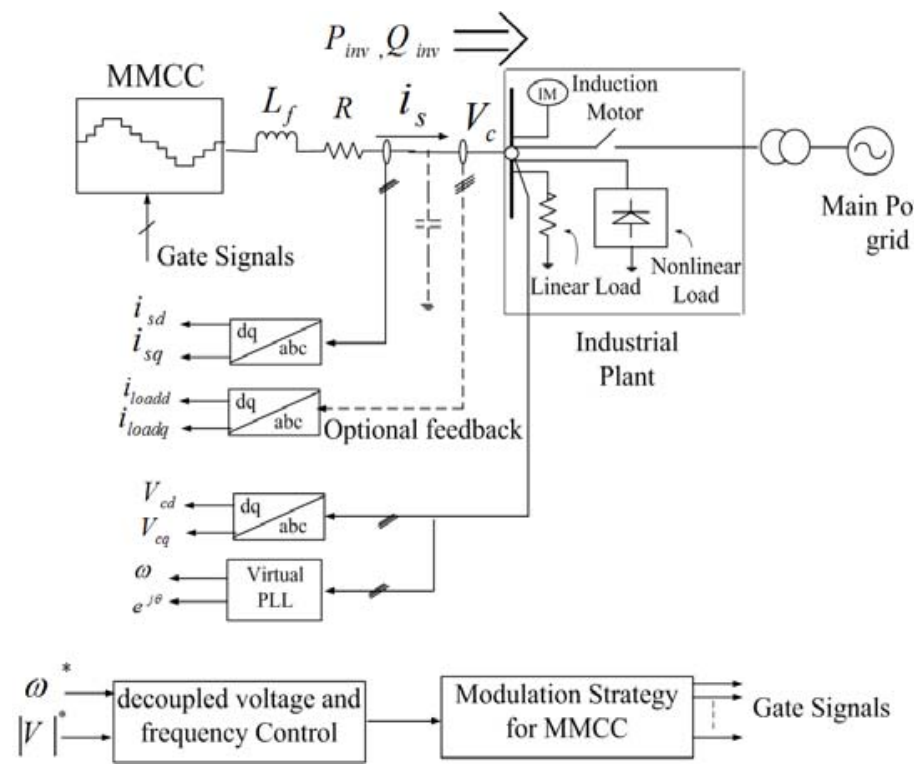

Fig. 6 Overview of the control strategy in grid independent mode

Fig. 6 shows the power injected by converter $P_{\text {inv }}, Q_{\text {inv. Any }}$ mismatch between power injected and demand causes voltage and frequency fluctuation. The real and reactive power of the grid independent plant can be described by using (13) and (14).

$$
\begin{aligned}
& P_{\text {inv }}=3 \frac{V_{c}^{2}}{R_{\text {load }}} \\
& Q_{\text {inv }}=3 V_{c}^{2}\left(\frac{1}{\omega L}-\omega C\right)
\end{aligned}
$$

Equation (13) may be expression as following

$$
V_{c}=\sqrt{\frac{1}{3} P_{\text {inv }} R_{\text {load }}}
$$

Therefore, voltage $\left(\mathrm{V}_{\mathrm{c}}\right)$ is function of real power $(\mathrm{P})$ of the converter and frequency ( $\mathrm{f}$ ) is a function of both real $(\mathrm{P})$ and reactive power $(\mathrm{Q})$ in grid independent mode.

The desired voltage $V_{c}$ can be controlled by controlling only real power. The objective of the voltage control strategy is to control $\mathrm{V}_{\mathrm{cd}}$ and $\mathrm{V}_{\mathrm{cq}}$ to their reference $\mathrm{V}_{\text {cdref }}$ and $\mathrm{V}_{\text {cqref }}$ respectively. The outer $\mathrm{V}_{\mathrm{cd}}$ and $\mathrm{V}_{\mathrm{cq}}$ loop provides information to $i_{\text {sd }}$ and $i_{s q}$ which are used to control the real and reactive power of the converter. Fig. 7 shows the entire voltage control strategy. The frequency which forces $\mathrm{V}_{\text {cd }}$ to zero can be estimated for the virtual PLL (under fixed frequency control) In steady state total grid independent plant, voltage is predominantly maintained by $\mathrm{V}_{\mathrm{sq}}$ which is essentially controlled by $i_{\text {sq }}$.

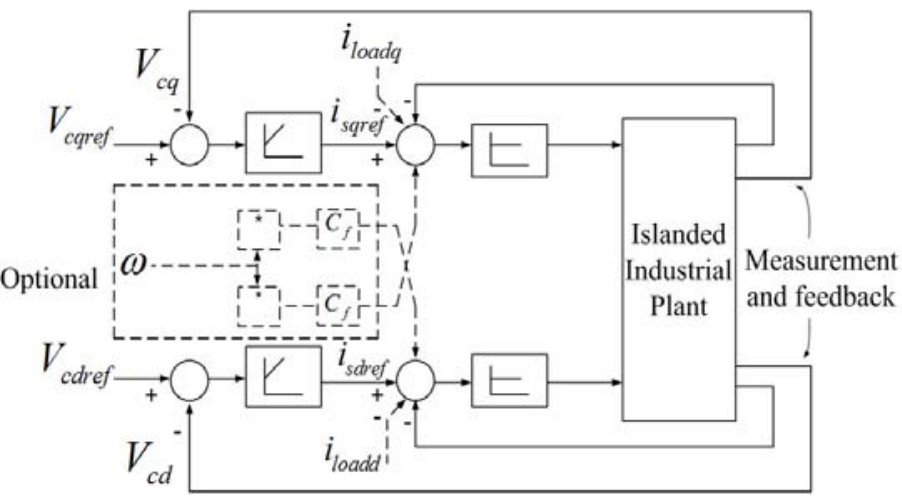

Fig. 7 Voltage Control Strategy (blocks in dotted are not required for filterless operation)

\section{E. Frequency Control - Fixed Frequency, Virtual PLL}

In grid connected mode the frequency is measured by forcing $\mathrm{V}_{\mathrm{cd}}$ to zero. However, such a strategy is not valid in grid independent mode [16] where frequency is measured by using a filter $\mathrm{H}(\mathrm{s})$ which processes $\mathrm{V}_{\mathrm{cd}}$ as shown in (16) and (17).

$$
\begin{aligned}
& \omega(s)=H(s) V_{c d}(s) \\
& H(s)=\frac{K_{\Phi}\left(1+s T_{1}\right)}{s\left(1+s T_{2}\right)}
\end{aligned}
$$

The filter must be of the form of an integrator as there should be at least one pole to ensure zero steady state error. A compensator may be required to improve high frequency response of the controller. In the case of filterless operation the strategy slightly modifies as shown in Fig. 8 and becomes current based control rather than voltage based strategy.

\section{F. Frequency control -Proposed $Q-f / P-V$ droop}

Frequency of the grid independent plant can be maintained to a stable point provided real and reactive power are controlled properly. A disturbance in frequency occurs when a reactive load such as large induction machine switches on which draws mainly reactive current while starting. Frequency fluctuation also occurs when a fault occurs on the ac bus. The proposed scheme, as shown in Fig. 9, uses $\mathrm{P}-\mathrm{V}$ droop and $\mathrm{Q}$ - $f$ droop strategy which implies real power $P_{\text {inv }}$ is controlled for maintaining the voltage while $Q_{\text {inv }}$ is controlled for maintaining frequency.

\section{CASE STUDIES AND RESULTS}

The customer load was modeled as a $50 \mathrm{~Hz}$ Industrial plant with a combination of three types of load - linear, nonlinear and an induction motor. This type of load often has voltage dip problems on motor starting and it could be difficult to maintain stability because of low system inertia. The control strategies with and without filter structure were modeled in MATLAB/SIMULINK. Simulations of load switching, voltage control, motor starting, frequency control and fault conditions were undertaken using an MMCC with small ' $L$ ' filter and conventional system with bulky LC filter based on parameters 
given in Table II. The following comparisons and testing was undertaken.
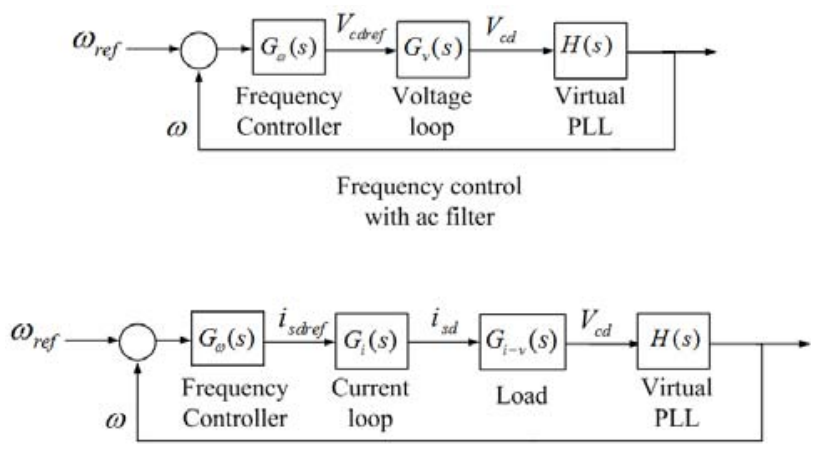

\section{Frequency control in} filterless structure

Fig. 8 Proposed Frequency Control Scheme with and without ac filter

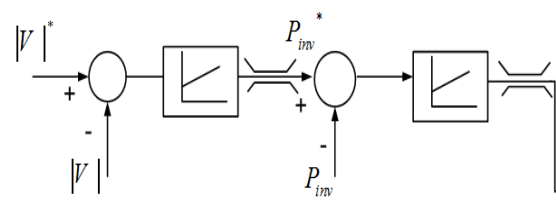

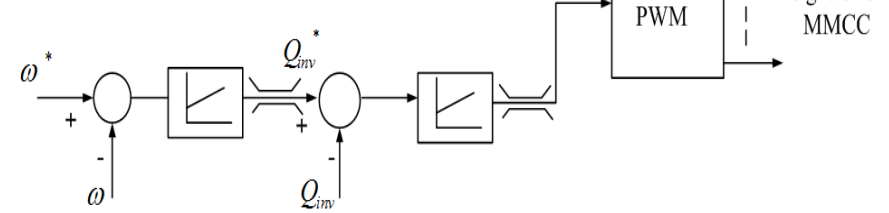

Fig. 9 Combined voltage- frequency control scheme based on $\mathrm{Q}-\mathrm{f} / \mathrm{P}-\mathrm{V}$ droop

A. Load Power Quality Conventional System and MMCC

The Table III shows the comparison of THD of a conventional two-level converter and MMCC using only an $\mathrm{L}_{\mathrm{f}}$ filter. It can be seen that the power quality is comparable and that both converter types are capable of meeting standards such as IEEE 519.

\section{B. Test of Voltage and Q-f Droop Frequency Controller}

The Voltage and frequency controllers were tested under simulation by firstly step changing the voltage setpoint and showing that the ' $\mathrm{d}$ '-axis current and frequency remains unaffected (Fig 10) and then step changing the frequency which cause the ' $d$ '-axis current to change which signifies that frequency of the plant depends on mainly reactive power (Fig 11). The response shows stable performance without any overshoot.

TABLE II.

SYSTEM PARAMETERS FOR TEST SYSTEM

\begin{tabular}{|l|l|c|}
\hline \multicolumn{1}{|c|}{ Symbols } & \multicolumn{1}{|c|}{ Quantity } & Value \\
\hline & \multicolumn{1}{|c|}{ Nominal Power Level } & $10 \mathrm{MW}$ \\
\hline $\mathrm{V}_{\mathrm{c}}$ & Plant Nominal Voltage & $3.3 \mathrm{kV}(\mathrm{L}-\mathrm{L})$ \\
\hline $\mathrm{i}_{\mathrm{s}}$ & $\begin{array}{l}\text { Nominal Current of the } \\
\text { converter }\end{array}$ & $2 \mathrm{kA}$ \\
\hline $\mathrm{i}_{\text {load }}$ & Nominal Load Current & $1.75 \mathrm{kA}$ \\
\hline
\end{tabular}

\begin{tabular}{|l|l|c|}
\hline \multicolumn{1}{|c|}{ Symbols } & \multicolumn{1}{|c|}{ Quantity } & Value \\
\hline & \multicolumn{1}{|c|}{ Nominal Power Level } & $10 \mathrm{MW}$ \\
\hline & Nominal Frequency & $50 \mathrm{~Hz}$ \\
\hline $\mathrm{L}_{\mathrm{f}}$ & Converter output inductor & $5 \mathrm{mH}$ \\
\hline $\mathrm{C}_{\mathrm{dc}}$ & DC-link capacitance & $3.3 \mathrm{mF}$ \\
\hline $\mathrm{L}_{\text {boost }}$ & $\begin{array}{l}\text { Boost Inductor for dc-dc } \\
\text { converter }\end{array}$ & $3 \mathrm{mH}$ \\
\hline
\end{tabular}

TABLE III. THD COMPARISON UNDER STEADY STATE OPERATION

\begin{tabular}{|c|c|}
\hline Converter & THD \\
\hline 2-stage conventional & $0.25 \%$ of fundamental \\
\hline MMCC (13 level) with L filter & $0.28 \%$ of fundamental \\
\hline
\end{tabular}
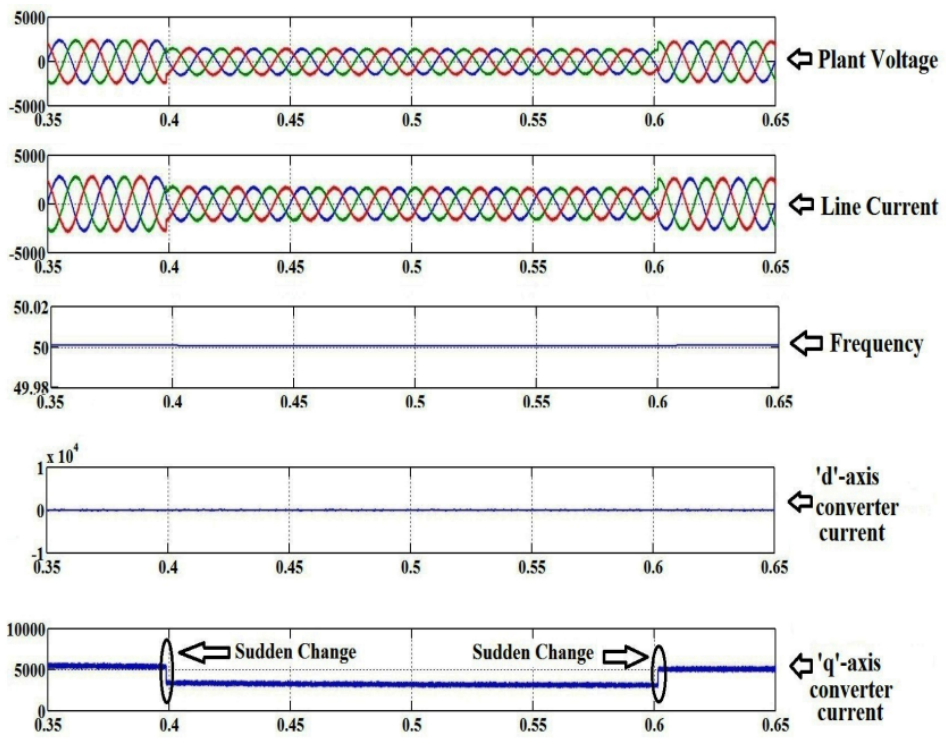

Fig. 10 Test of voltage controller - response of voltage and frequency of the islanded plant using MMCC based ESS
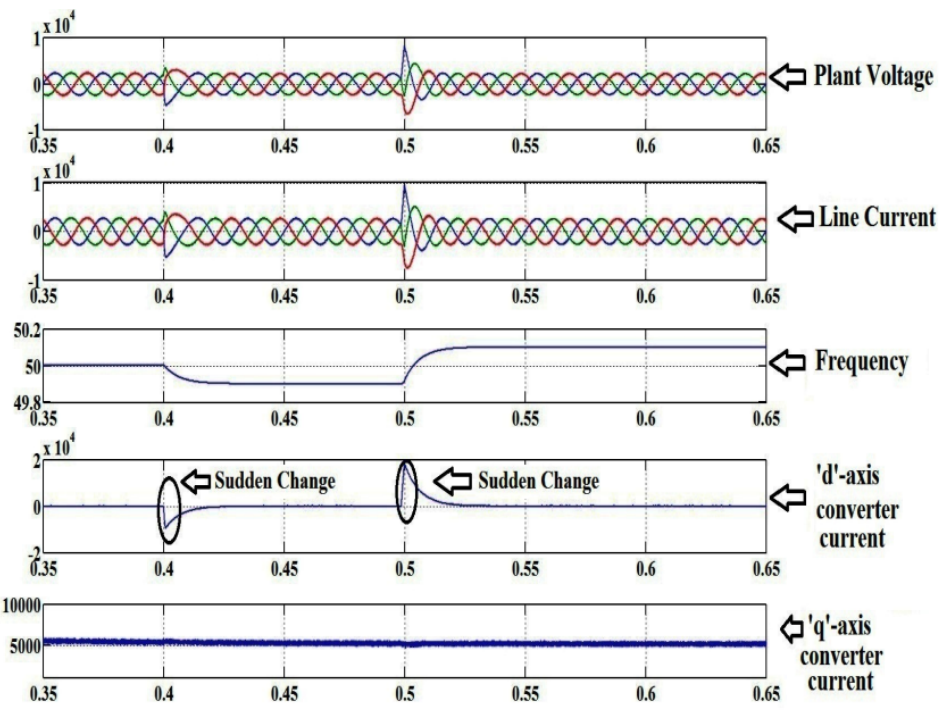

Fig. 11 Test of frequency controller - response of current and voltages of the islanded plant using MMCC based ESS 


\section{C. load switching-operation under linear load load}

Fig. 12 shows the response of the grid independent voltage, frequency and current using an MMCC when an additional 10MW resistive load step is switched on at $\mathrm{t}=0.6 \mathrm{~s}$. This demonstrates the overloading capacity of the proposed ESS because of potentially available redundant modules. Redundant modules can become active in the time of extra load switches/fault. The response demonstrates there is almost no change in grid independent voltage in spite of heavy load switching.
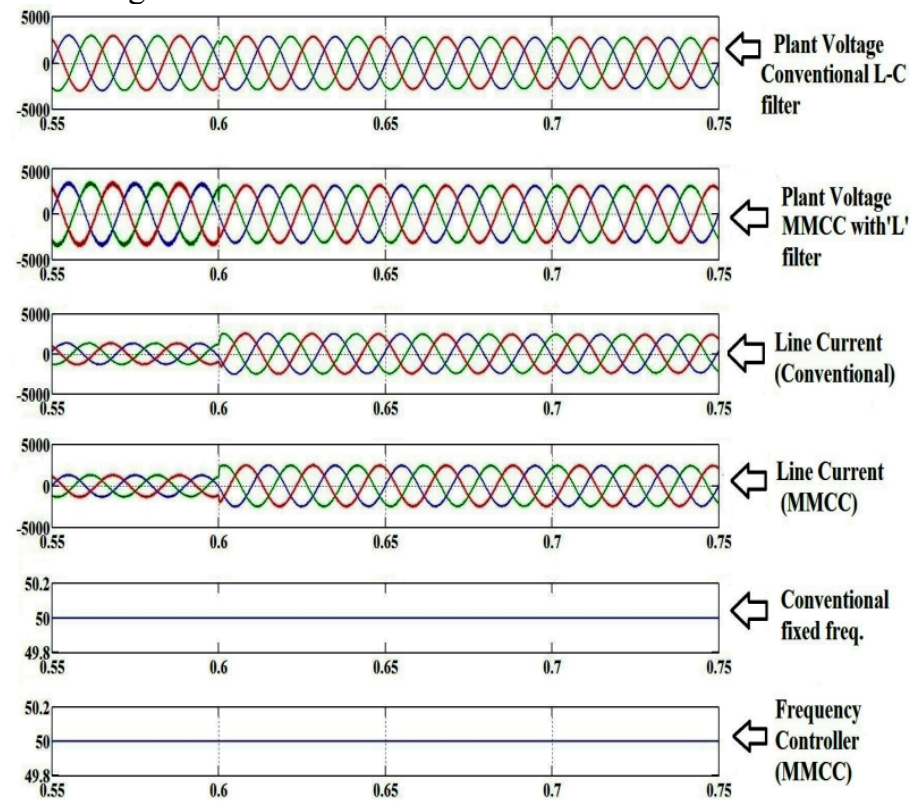

Fig. 12 Sudden load switching - response of voltage, current and frequency of the grid independent plant using conventional and MMCC based ESS

D. load switching-operation under nonlinear load

Fig. 13 shows the response of the grid independent voltage frequency and current using an MMCC when an additional nonlinear load step is switched on at $\mathrm{t}=0.6 \mathrm{~s}$. It shows that there is sudden drop in system frequency. This is because the nonlinear load suddenly draws some reactive current which causes the frequency to change. It can be seen that the frequency controller acts and maintains the frequency back to $50 \mathrm{~Hz}$. The response demonstrates there is almost no change in grid plant voltage in spite of heavy load switching. The, MMCC converter can maintain a sinusoidal voltage using only an 'L'-filter.

\section{E. Induction Machine switching}

Industrial plant with pumps, fans and compressors may have direct on-line start induction motors driving these. Induction machines without soft start can draw a high in-rush current and consume reactive power. The controller response is shown in Fig 14 which shows a sudden change in 'in frequency when a $1 \mathrm{MW}$ induction motor is switched on. The controller tracks the reference value without oscillation or overshoot.
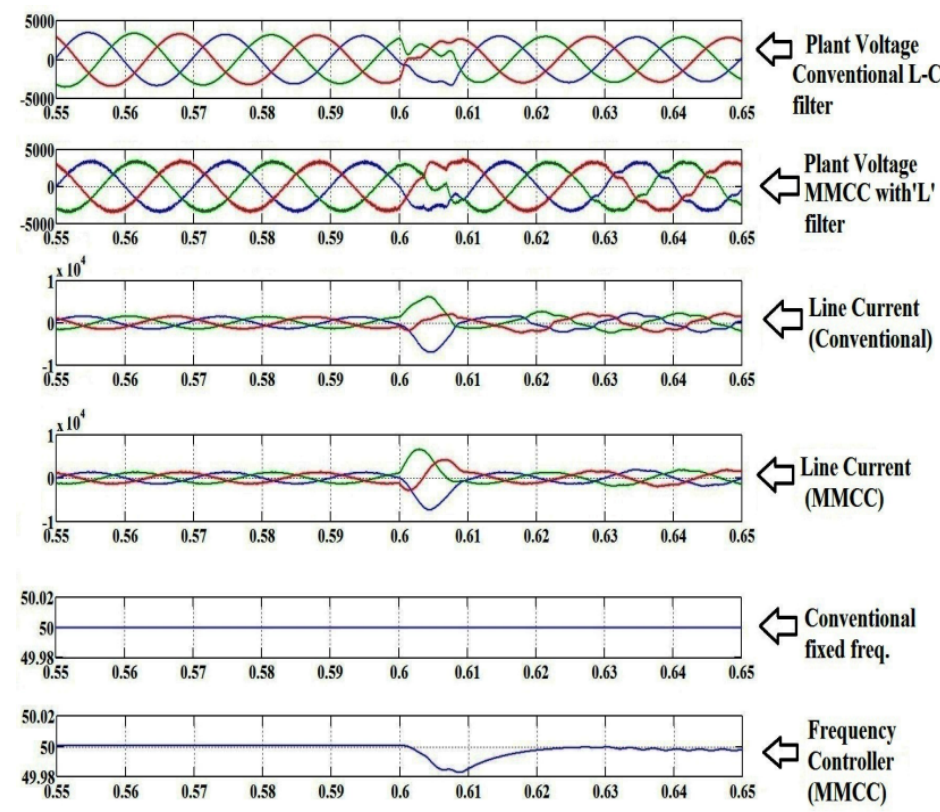

Fig. 13 Operation under nonlinear load - response of voltage, current and frequency of the grid independent plant using conventional and MMCC ESS
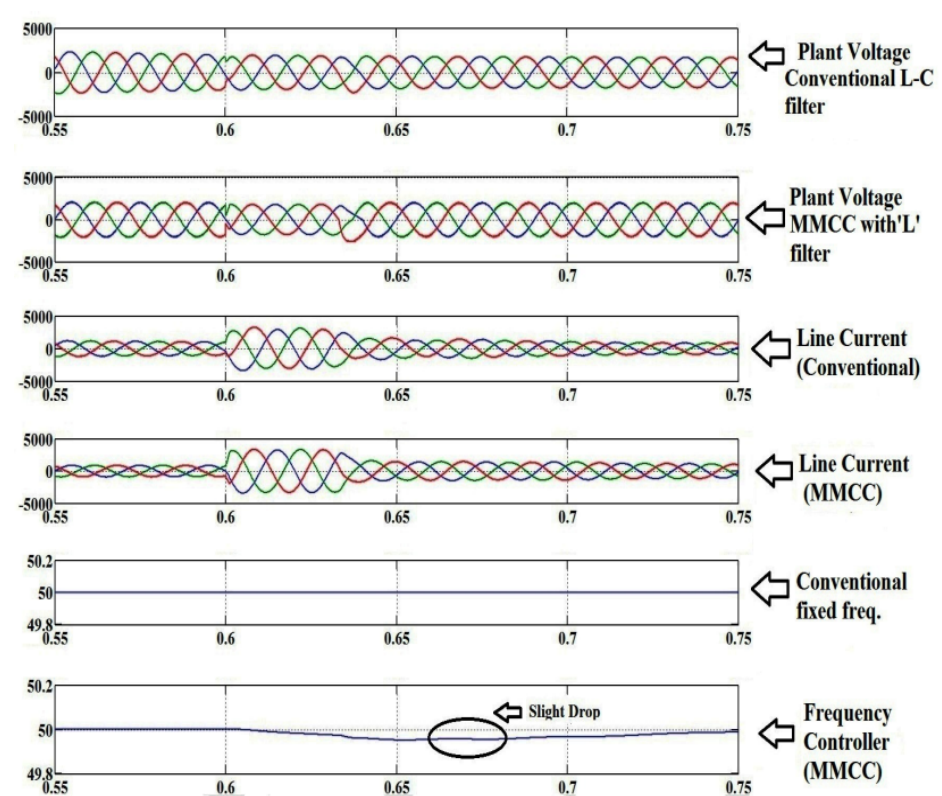

Fig. 14 Operation of industrial plant under sudden switching of induction motor - response of voltage and frequency of the grid independent plant using conventional and MMCC ESS

\section{F. Fault/ Short Circuit}

It is not unusual to have faults on the ac system. Fig. 15 shows effect of a single phase L-E fault on an industrial plant using a conventional two-level converter as well as using an MMCC. A single phase to ground faults at $t=0.6 \mathrm{~s}$ is simulated. The response of the voltage, current and frequency have been shown. It is to be noted that imbalance causes a $100 \mathrm{~Hz}$ oscillation in frequency. However, the magnitude of this oscillation is negligible because the control bandwidth is kept well below $100 \mathrm{~Hz}$. 

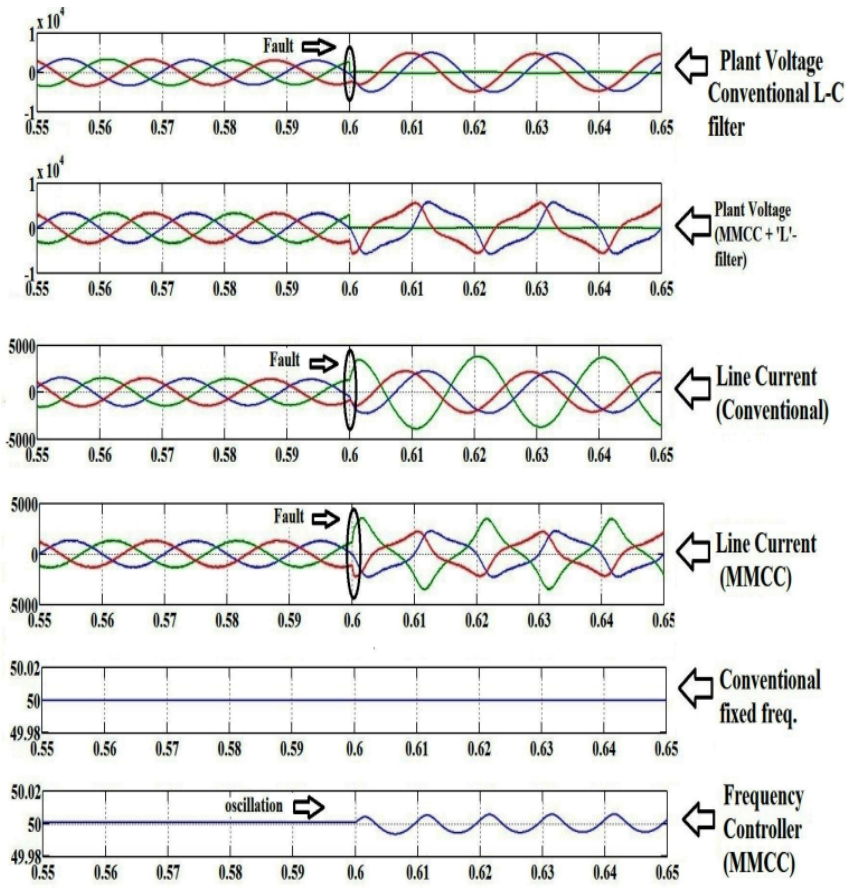

Fig. 15 Operation of industrial plant under L-E fault - response of voltage and frequency of the grid independent plant using conventional and MMCC based ESS

\section{CONCLUSION}

A multilevel converter with module redundancy using second-life batteries to meet reliability requirements for grid independent support functionality has been described. A Second-life battery based ESS is attractive because it could be available at lower cost compared to a conventional ESS. A Modular converter structure is preferable for this type of ESS in order to get reasonable reliability. This can also lead to filter size reduction or elimination.

Traditionally fixed frequency control is used. A virtual PLL measurement could be used to enhance the transitioning of this mode to P-f droop. An alternative voltage and frequency control strategy based on $\mathrm{Q}-\mathrm{f}$ droop has been introduced for this converter in grid independent operation without additional generation which maintains stable voltage and frequency without using additional sensors above that needed by a conventional system. The operation of the controller has been simulated under different conditions such as faults, motor starting and load switching. It was shown that the modular converter with second-life batteries performs in a comparable manner to a conventional topology under most normal operating conditions. However, there could be a slight drop in power quality under unbalancing or nonlinear load switching if the filter capacitor is completely eliminated. Future research work would consider of using such modular converter with $\mathrm{Q}$ - $\mathrm{f}$ droop control to mitigate voltage drop in grid independent mode.

\section{ACKNOWLEDGMENT}

The authors would like to thank the EPSRC (EP/1008764/1) UK for funding this work

\section{REFERENCES}

[1] Arup and Cenex, "Investigation into the Scope for the Transport Sector to Switch to Electric Vehicles and Plugin Hybrid Vehicles", Department of Transport, October 2008

[2] Viswanathan, V.V.; Kintner-Meyer, M.; , "Second Use of Transportation Batteries: Maximizing the Value of Batteries for Transportation and Grid Services," Vehicular Technology, IEEE Transactions on , vol.60, no.7, pp.2963-2970, Sept. 2011

[3] C. Du, E. Agneholm, and G. Olsson, "Use of VSC-HVDC for industrial systems having onsite generation with frequency control," Power Delivery, IEEE Transactions on, vol. 23, no. 4, pp. 2233-2240, 2008.

[4] Davis, W.K.; Stratford, R.P.; , "Operation of UPS on emergency generation," Industrial and Commercial Power Systems Technical Conference, 1988. Conference Record, Papers Presented at the 1988 Annual Meeting., vol., no., pp.11-14, 2-5 May 1988

[5] Abusara, M.A.; Sharkh, S.M.; , "Control of line interactive UPS systems in a Microgrid," Industrial Electronics (ISIE), 2011 IEEE International Symposium on , vol., no., pp.1433-1440, 27-30 June 2011

[6] N. Mukherjee, D.Strickland, A.Cross, W.Hung; "Reliability Estimation of second life Battery System Power Electronic topologies for Grid Frequency Response Applications", Power Electronics, Machines and Drives (PEMD 2012), 6th IET International Conference on, vol., no., pp., March 2012

[7] Trintis, I.; Munk-Nielsen, S.; Teodorescu, R.; , "Cascaded H-bridge with bidirectional boost converters for energy storage," Power Electronics and Applications (EPE 2011), Proceedings of the 2011-14th European Conference on , vol., no., pp.1-9, Aug. 30 2011-Sept. 12011

[8] Akagi, H.; , "Classification, terminology, and application of the modular multilevel cascade converter (MMCC)," Power Electronics Conference (IPEC), 2010 International, vol., no., pp.508-515, 21-24 June 2010

[9] Heng Deng; Oruganti, R.; Srinivasan, D.; , "Modeling and Control of Single-Phase UPS Inverters: A Survey," Power Electronics and Drives Systems, 2005. PEDS 2005. International Conference on , vol.2, no., pp. 848- 853, 28-01 Nov. 2005

[10] Kahrobaeian, A.; Mohamed, Yasser A.-R. I.; , "Smart control interface for robust operation of DG units in grid connected and Grid independent modes," Innovative Smart Grid Technologies (ISGT), 2012 IEEE PES, vol., no., pp.1-8, 16-20 Jan. 2012

[11] Du, C.; Agneholm, E.; Olsson, G.; , "Comparison of Different Frequency Controllers for a VSC-HVDC Supplied System," Power Delivery, IEEE Transactions on , vol.23, no.4, pp.2224-2232, Oct. 2008

[12] Kottick, D.; Blau, M.; Edelstein, D.; , "Battery energy storage for frequency regulation in an island power system," Energy Conversion, IEEE Transactions on , vol.8, no.3, pp.455-459, Sep 1993

[13] Mercier, P.; Cherkaoui, R.; Oudalov, A.; , "Optimizing a Battery Energy Storage System for Frequency Control Application in an Isolated Power System," Power Systems, IEEE Transactions on , vol.24, no.3, pp.14691477, Aug. 2009

[14] Thomas, S.; Stieneker, M.; De Doncker, R.W.; , "Development of a modular high-power converter system for battery energy storage systems," Power Electronics and Applications (EPE 2011), Proceedings of the 2011-14th European Conference on , vol., no., pp.1-10, Aug. 30 2011-Sept. 12011

[15] Bragard, M.; Soltau, N.; Thomas, S.; De Doncker, R.W.; , "The Balance of Renewable Sources and User Demands in Grids: Power Electronics for Modular Battery Energy Storage Systems," Power Electronics, IEEE Transactions on, vol.25, no.12, pp.3049-3056, Dec. 2010 